\title{
Outstanding Reviewer Award 2018
}

๑) Springer-Verlag GmbH Germany, part of Springer Nature 2019

The editors and publisher of OR Spectrum are pleased to announce the following reviewers who have done an outstanding job in submitting reviews during the time of origin of volume 40 :

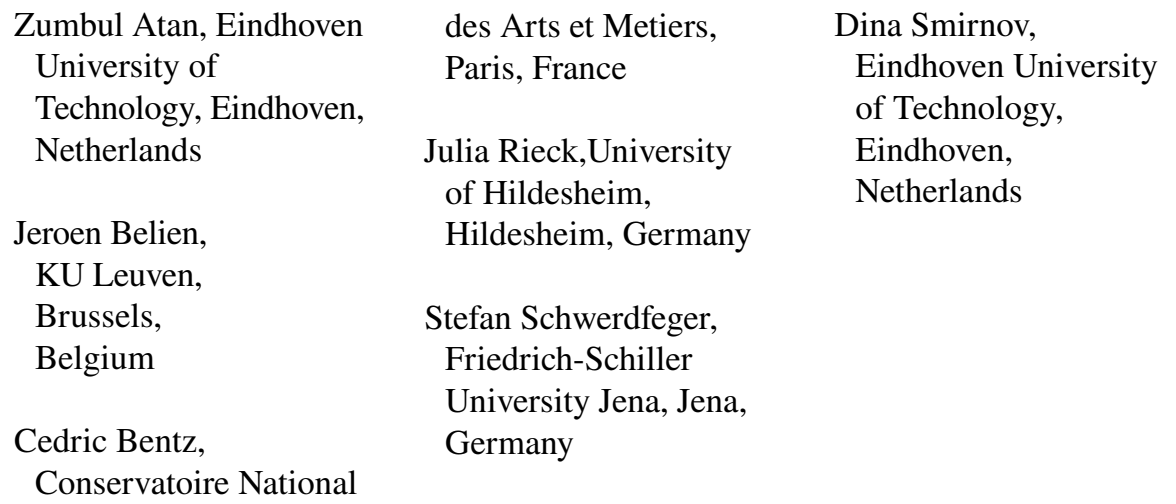

Publisher's Note Springer Nature remains neutral with regard to jurisdictional claims in published maps and institutional affiliations. 